$\begin{array}{rll}\text { Artvin Çoruh Üniversitesi } & \text { Artvin Coruh University } \\ \text { Orman Fakültesi Dergisi } & \text { Journal of Forestry Faculty } \\ \text { ISSN:2146-1880, e-ISSN: 2146-698X } & \text { ISSN:2146-1880, e-ISSN: 2146-698X } \\ \text { YII: 2015, Cilt: 16, Sayı:1, Sayfa: 65-71 } & \text { Year: 2015, Vol: 16, Issue: 1, Pages: 65-71 }\end{array}$

http://edergi.artvin.edu.tr

Araştırma makalesi

\title{
Dış ortam koşullarında bazı poliüretan esaslı üst yüzey sistemlerinin odun yüzeyini koruma performansı
}

\section{Protection performance of some polyurethane surface systems on wood surface in outdoor conditions}

Özlem ÖZGENÇ

Karadeniz Teknik Üniversitesi, Orman Fakültesi, Orman Endüstri Mühendisliği Bölümü

Özet

Bu çalışmada, iki farklı üst yüzey sistemi uygulanan doğu ladini (Picea orientalis L.) test ve kontrol odunlarının dış ortam koşullarına olan dayanımı araştırılmıştır. Üst yüzey sistemi olarak, iki farklı poliüretan esaslı maddeler karşılaştırılmıştır. Dış ortam testi; farklı rakımlardaki Sürmene sahil, Uzungöl ve Hıdırnebi yaylalarında uygulanmıştır. Doğu ladini örnekleri, dış hava koşullarında renk değişimi ve basınç direncindeki azalma oranı esas alınarak karşılaştırılmıştır. En düşük renk değişimi ve basınç direncindeki azalma Hıdırnebi yaylasında bulunmuştur. Elde edilen sonuçlara göre; polyester esaslı maddenin, dış ortam koşullarında renk değişimi ve basınç direncindeki azalmaya karşı doğu ladini odununu oldukça iyi koruduğu belirlenmiştir.

Anahtar kelimeler: Basınç direnci, dış ortam testi, doğu ladini, poliüretan, renk değişimi

\section{Abstract}

In this study, two different surface system applied oriental spruce (Picea orientalis L.) were investigated resistance to the outdoor conditions of the test and control wood. Surface systems were compared as two different property polyurethane-based materials. Outdoor test has been implemented in Sürmene coastal, Uzungol and Hıdırnebi plateaus. Oriental spruce samples were compared based on the discoloration and reduction in fiber to parallel compressive strength in outdoor conditions. The weathering test in Hıdırnebi plateau was found at the lowest discoloration and reduction rate on compressive strength. According to the obtained results; polyester-based material, the oriental spruce wood against discoloration and reduction in compressive strength was determined at outdoor conditions is relatively well preserved.

Key words: Compression strength, discoloration, oriental spruce, outdoor test, polyurethane

\section{Giriş}

Ahşap uygun koşullarda dayanıklı bir malzeme olup, yüzyıllardır yapı malzemesi olarak kullanılmaktadır. Diğer biyolojik malzemeler gibi, çevresel bozunmaya yatkın olması nedeniyle açık alan uygulamalarında kullanılan ağaç malzeme, doğal çevre şartlarına maruz kaldığında hizmet ömrü kısalmaktadır. Dış ortam koşullarında toprak üstünde kullanılan ahşap malzemenin kimyasal, mekanik ve güneş ışını etmenlerinin birleşimi ile bozunması "weathering" olarak tanımlanmaktadır (Özgenç 2014). Bu bozunma sürecini UV ışını başlatmakta ve dış ortam koşullarında bulunan nem, sıcaklık, oksijen, rüzgâr, kirlilik ve diğer benzer etmenler söz konusu bozunmayı arttırmaktadır. (Pandey 2005, Williams 2005). Ahşap malzemenin dış ortamda bozunmadan korunması için çok sayıda yöntem geliştirilmiştir. Bu yöntemlerden biri; krom, demir ve bakır gibi suda çözünen maddelerle emprenye işlemidir (Temiz 2005). Ayrıca kimyasal modifikasyonlar odun yüzeyine, dış ortam koşullarında yüksek renk stabilitesi kazandırmaktadır (Yalınkılıç ve ark. 1999, Zhang ve ark. 2009). Isıl işlem ile modifiye edilen odun yüzeyi fotodegredasyona karşı direnç kazanmaktadır. Isıl işlem dış ortam koşullarına maruz kalan odun yüzeyinde ligninin foto degredasyonunu önleyerek renk stabilizasyonunu sağlamaktadır (Ayadi ve ark. 2003).

Ahşap malzeme yüzeyinin UV etkisine karsı korunmasında kullanılan bir başka yöntem, yüzey işlemleri (boyalar, vernikler, cilalar, su itici maddeler 
vb.) uygulayarak, UV ışınının ve yağmur suyunun odun yüzeyiyle temasının kesilmesidir (Özgenç ve ark. 2012). Liflevha, yongalevha ve masif odun gibi malzemeler dışarıdan gelen UV etkisine karşı farklı tip kaplamalar ile korunmaktadır (Burdurlu ve Özgenç 2009). Fakat günümüzde masif ağaç malzemenin dış ortam koşullarına karşı korunması için, çok sayıda farklı üst yüzey ürünleri piyasaya sunulmuştur (Decker ve ark. 2004, Evans ve Chowdhury 2010).

Polimer esaslı vernikler yüksek nem içeren şiddetli çevre koşullarına karşı bir hayli dayanıklı olmaktadır. Yang ve ark. (2002) poliüretan verniğin suya karşı dayanımını ve değişen morfolojik özelliklerini incelediklerinde, hidrofilik grupların yapısındaki değişim nedeniyle yüzeyde ince çatlaklar oluştuğunu tespit etmişlerdir. Poliüretan esaslı vernik uygulanan odun yüzeyleri dış ortam koşullarına maruz kaldığında yüksek renk değişimi göstermektedir (Özgenç ve ark. 2013). Ayrıca dış ortam koşullarında su, oksijen ve UV ışını etkisi ile zaman içerisinde bozunan poliüretan esaslı üst yüzey işleminde pigment kayıpları ve kopmalar oluşmaktadır. UV absorbe eden pozitif etkisi ile polyester-üretan üst yüzey kaplamaları dış ortam koşullarına uygun olmaktadır. (Croll ve Skaja 2002). Bazı odun türlerinin yüzeyinde su itici etkisi olan poliüretan vernik uygulandığında dış ortam koşullarında oluşan renk koyulaşmasının geciktirildiği tespit edilmiştir. Ayrıca dış ortam koşullarında odun yüzeyinde artan pürüzlülük önlenmektedir (Nzokou ve ark. 2011).

Bu çalışmada, Doğu Karadeniz Bölge'sinde ahşap yayla evi yapımında önemli oranda değerlendirilen doğu ladini türü denemeye alınmıştır. Poliüretan ve polyester esaslı üst yüzey işlemleri uygulanan ahşap malzeme örnekleri birbirinden farklı yükseltilerde bulunan 3 pilot bölgede (Hıdırnebi Yaylası, Uzungöl Yaylası ve Sürmene sahil kesimi) 15 ay süre ile doğal dış ortam koşulları testine maruz bırakılmıştır. UV ışını, yağmur ve rüzgâr gibi çeşitli etmenlerden dolayı odun örnekleri yüzeylerindeki renk değişimi değerleri ölçülerek en iyi performansı veren işlemler araştırılmıştır. Ayrıca açık hava testine maruz kalan işlem uygulanmayan ve poliüretan ve polyester esaslı üst yüzey işlemleri uygulanan odun örneklerinin liflere paralel basınç direnci değerlerindeki kayıp oranı belirlenerek karşılaştırılmıştır.

\section{MATERYAL ve YÖNTEM}

\section{Odun Örneklerinin Hazırlanması}

Doğal açık hava koşulları testi için, doğu ladini (Picea orientalis L.) diri odunundan $300 \times 70 \times 20$ (boyuna $\times$ teğet $x$ radyal) $\mathrm{mm}$ boyutlarında kesilen örnekler; $20^{\circ} \mathrm{C}$ sıcaklık ve \% 65 bağıl nem ortamında üç hafta süre ile klimatize edilmiştir.

\section{Üst Yüzey Maddesi ve Yöntemi}

Induline SW 900: Remmers şirketi tarafından üretilen\% 1,2 propikazol, \% 0,3 jodpropinil-butilkarbomat ve hibrit reçineleri içeren su bazlı, emprenye ve ahşap sertleştiricisidir. Induline SW-900 alt katmana (ahşap) mükemmel nüfuz etmektedir. Yarı şeffaf boya işlemlerinde lekelenmeyi önlemekte ve ahşap liflerini dikey konuma getirerek sertleştirmektedir. Böylelikle liflerin ilk zımparada tamamen alınmasına olanak sağlamaktadır. Su bazlı boya sistemlerinde istenmeyen lekelenmeleri önlemekte ve homojen yüzey oluşturmakta olduğu için yaygın olarak üst yüzey uygulamalarında astar katman olarak uygulanmaktadır.

UCOAT UX-310: Sanyo kimyasal firması tarafından üretilen poliüretan: N-Methyl-2-pyrolidane (NMP) esaslı olup, elastik ve oldukça esnek bir film oluşturmaktadır. Naylon ve metaller gibi materyallerin yapıştırılmasında kullanılmaktadır.

UCOAT UWS-145: Sanyo kimyasal firması tarafından üretilen poliüretan: polyester esaslı poliüretan madde olup odun yüzeyinde emülsiyon elastik ve oldukça sert bir film oluşturmaktadır. Odun yüzeyinde parlak bir görünüm oluşturmaktadır. 
Çizelge 1. Doğal dış ortam testi için hazırlanan örnek varyasyonları.

\begin{tabular}{ll}
\hline Varyasyon & Uygulanan İşlemler \\
\hline Kontrol Grubu & Kontrol Grubu \\
\hline X Maddesi & $\begin{array}{l}\text { Induline SW 900+ UCOAT UX-310+ } \\
\text { Sanprene C-810 }\end{array}$ \\
\hline Y Maddesi & $\begin{array}{l}\text { Induline SW 900+ UCOAT UX-310+ UCOAT } \\
\text { UWS-145 }\end{array}$ \\
\hline
\end{tabular}

\section{Doğal Dış Ortam Testi}

Açık hava koşulları testi için, $300 \times 70 \times 20 \mathrm{~mm}$ boyutlarında hazırlanan test ve kontrol grubu örneklerinin rutubet alarak çürümesini önlemek için 2Epoksi beyaz boya ile enine kesitlerle birlikte TS EN 927-3 standardında gösterilen bölgeler boyanmıştır. Daha sonra odun örnekleri, açık hava testi öncesinde 20 OC sıcaklık \% 65 \pm 5 bağıl neme sahip ortamda yaklaşık 2 hafta bekletilmiştir.

Türkiye'nin Doğu Karadeniz Bölgesi illerinden Trabzon'da yer alan farklı rakımlardaki Uzungöl (1090 $\mathrm{km})$, Sürmene sahil kesiminde $(0 \mathrm{~km})$ ve Hıdırnebi (1600 km) yaylalarında, açık hava koşulları test düzenekleri kurulmuştur. TS EN 927-3 standardında belirtildiği gibi Uzungöl ve Hıdırnebi yaylalarında kurulan düzeneklere, Eylül-2012 tarihinde kontrol ve test örnekleri yerleştirilmiştir. Açık hava koşulları testi, 12 ay süre ile devam ettirilmiştir.

\section{Renk Ölçümü}

Konica Minolta CD-600 marka renk ölçüm cihazı ile hazırlanan test ve kontrol örneklerinin doğal açık hava koşulları testi öncesindeki renk ölçüm analizleri ISO 7724 standartlarına uygun olarak gerçekleştirilmiştir. Doğal açık hava koşulları testi için hazırlanan örneklerde 8 farklı noktadan renk ölçümü yapılarak ortalamaları alınmıştır. CIELab (Commission Interational de i'Eclairage) sistemi üç parametreden oluşmaktadır: $L^{*}$ : ışık stabilitesi, $a^{*}$ ve $b^{*}$ kromotografik koordinatları, ( +a* kırmızı için, -a* yeşil için, $+b^{*}$ sarı için, $-b^{*}$ mavi için kullanılmaktadır). $L^{*}, a^{*}$ ve $b^{*}$ değerleri, farklı sürelerde açık hava testine tutulan örneklerde belirlenerek meydana gelen renk değişiklikleri $\left(\Delta \mathrm{E}^{*}\right)$ aşağıdaki formül 1'ye göre belirlenmektedir:
$\Delta \mathrm{E}^{*}=\left(\Delta \mathrm{L}^{* 2}+\Delta \mathrm{a} * 2+\Delta \mathrm{b}^{* 2}\right)^{1 / 2}$

$\Delta \mathrm{L}^{*}$ : Işık stabilitesi,

$\Delta a^{*}:$ Kırmızı-yeşil stabilite,

$\Delta b^{*}$ : Sarı-mavi stabilite değerlerini ifade etmektedir.

\section{LPB Direnci Testi}

LPB direnci deneyleri TS 2595'e göre yürütülmüştür. 20 x $20 \times 30 \mathrm{~mm}$ (radyal x teğet x boyuna) boyutlarında her bir varyasyon için 20 'şer adet olmak üzere test ve kontrol örneği hazırlanmıştır. Deneyler öncesi denge rutubetine getirilen örneklerin enine kesit boyutları (a $x$ b) belirlenmiştir. Deney hızı örnekler makinede 1.5-2 dakikada kırılacak şekilde ayarlanmış olup 2000 N'luk alandaki kırılma anındaki kuvvet $\left(F_{\max }\right)$ ölçülmüştür. LPBD aşağıdaki eşitlik (2) yardımıyla hesaplanmıştır.

$\operatorname{LPBD}\left(\mathrm{N} / \mathrm{mm}^{2}\right)=\mathrm{F}_{\max } /(\mathrm{axb})$

\section{BULGULAR VE TARTIŞMA}

\section{Renk Değişimi}

Şekil 2'de görüldüğü üzere ilk ölçümden itibaren en yüksek renk değişimi, Uzungöl yaylasındaki test ve kontrol örneklerinde oluşmuştur. Chou ve ark. (2008) çalışmalarında, poliüretan tip üst yüzey maddelerinin renk stabilizasyonunun oldukça yüksek olduğunu belirlemiştir. Bu çalışmada da, en düşük renk değişimi Hıdırnebi yaylasındaki poliüretan esaslı üst yüzey uygulanmış örneklerde belirlenmiştir. Kontrol örneklerine kıyasla, $X$ ve $Y$ üst yüzey maddesi uygulanan odun örneklerinde renk değişimi çok daha düşük bulunmuştur. Fakat en düşük renk değişimi, özellikle $Y$ maddesi uygulanan odun örneklerinde belirlenmiştir. Poliüretan esaslı üst yüzey maddesinin, odun yüzeyini dış ortam koşullarındaki renk değişimi gibi bozunmaya karşı oldukça iyi koruduğu benzer çalışmalarda ortaya konuşmuştur (Decker ve ark. 2004; Evans ve ark. 2010; Özgenç ve ark. 2014). 


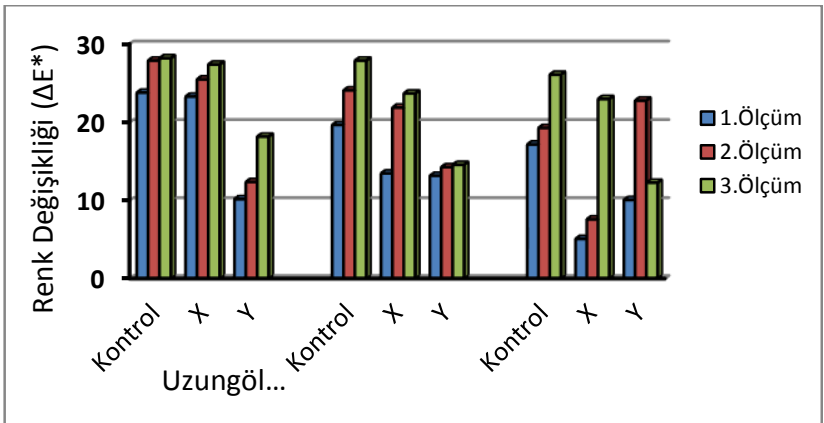

Şekil 2. Dış ortam testi sonrasında kontrol ve test örneklerindeki renk değişim

Doğu ladini örneklerinde meydana gelen ışık stabilitesi, kırmızı-yeşil stabilite, sarı-mavi stabilite değerleri ve renk değişim değerleri Tablo 2'de gösterilmiştir. $\Delta \mathrm{L}^{*}$ değerinde negatif yönde artış olmasının anlamı, örnek yüzeyinde beyaza doğru parlaklık artışıdır. Tablo 2 'de görüldüğü üzere, Uzungöl yaylasındaki örneklerin $\Delta L^{*}$ değerinde, negatif yöndeki artış oldukça yüksek olmuştur. Özellikle yüzeyine $Y$ maddesi uygulanan örneklerin $\left(\Delta L^{*}\right)$ değerinde negatif yöndeki artış en düşüktür. $\Delta a^{*}$ değeri ise; kontrol odunlarında negatif (yeşilimsi) yönde, $X$ ve $Y$ maddesi uygulanan odun örneklerinde pozitif (kırmızımsı) yönde değişim göstermiştir. $\Delta b^{*}$ değerindeki değişime bakıldığında; kontrol ve $Y$ maddesi uygulanan örneklerde negatif (mavimsi) yönde, $X$ maddesi uygulanan örneklerde pozitif (sarımsı) yönde değişim bulunmuştur.

Dış ortam koşulları maruziyeti sonrasında, $\mathrm{X}$ maddesinin odun örneklerinin kenarlarından koparak ayrıldığı gözlemlenmiştir. Chou ve ark. (2008), bazı poliüretan üst yüzey maddelerinin odun yüzeyinden koparak ayrıldığını belirleyerek benzer sonuçları ortaya koymuşlardır. $Y$ maddesinin ise, odun yüzeyini koruduğu deformasyona uğramadığı görülmüştür.
Doğu ladini kontrol örnek yüzeylerinde ise, çatlaklar ve bazı deformasyonlar oluşmuştur.

\section{LPB Direncinde Azalma}

Dış ortam koşullarına maruz kalan odun yüzeyinde çatlaklar, yarılmalar vb. deformasyonlar oluşmaktadır. Odun yüzeyindeki bu tip deformasyonlar da odunun LPB direnci azalmaya sebep olmaktadır (Ozgenc ve ark. 2013). Şekil 3'e bakıldığında görüldüğü üzere; LPB direncinde en yüksek azalma oranı kontrol örneklerinde, en düşük azalma oranı $Y$ maddesi uygulanan örneklerde görülmüştür. Kontrol ve test örneklerinin LPBD değerlerindeki en yüksek azalma oranı Sürmene sahil kesiminde, en düşük azalma oranı Hıdırnebi yaylasında uygulanan dış ortam testlerinde bulunmuştur.

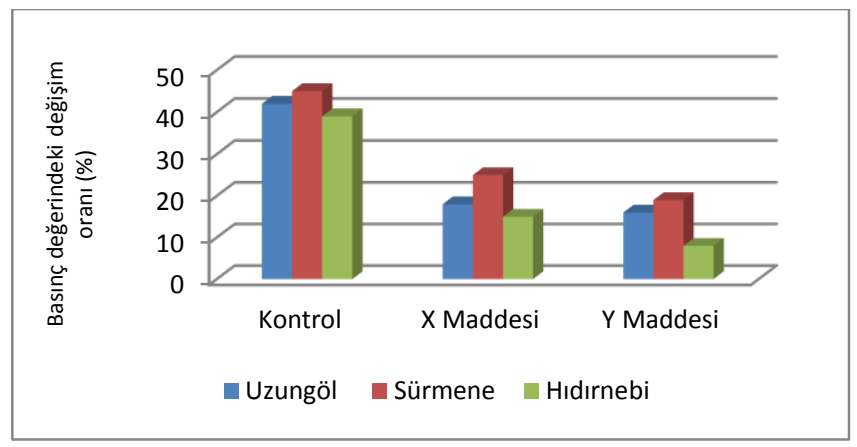

Şekil 3. Dış ortam testi sonrasında doğu ladini örneklerinin LPB direncinde değişim yüzdesi.

Çizelge 3'de görüldüğü üzere dış ortam testi nedeniyle LPB direncindeki en yüksek azalma, kontrol örneklerinde bulunmuştur. Dış ortam testi LPB direnci değerlerine göre, $X$ ve $Y$ maddesinin uygulanması basıncı az da olsa arttırmıştır. Ancak, dış ortam koşullarında LPB direncindeki azalma oranını, özellikle $Y$ maddesi önemli ölçüde düşürmüştür (Çizelge 3). 
Çizelge 2. Dış ortam testi öncesi ve sonrasında doğu ladini odunun değişim renk parametreleri

\begin{tabular}{|c|c|c|c|c|c|c|c|c|c|c|c|c|c|}
\hline & & \multicolumn{4}{|c|}{ Kontrol } & \multicolumn{4}{|c|}{ X Maddesi } & \multicolumn{4}{|c|}{ Y Maddesi } \\
\hline & & $\Delta \mathrm{L}^{*}$ & $\Delta a^{*}$ & $\Delta \mathrm{b}^{*}$ & $\Delta \mathrm{E}^{*}$ & $\Delta \mathrm{L}^{*}$ & $\Delta a^{*}$ & $\Delta b^{*}$ & $\Delta \mathrm{E}^{*}$ & $\Delta \mathrm{L}^{*}$ & $\Delta a^{*}$ & $\Delta b^{*}$ & $\Delta \mathrm{E}^{*}$ \\
\hline \multirow{3}{*}{ Uzungöl } & 1.Ölçüm & -15.8 & -1.8 & -17.7 & 23.8 & -19.6 & 8.9 & 6.9 & 23.3 & -12.4 & 4.4 & -0.4 & 13.2 \\
\hline & 2. Ölçüm & -20.1 & -2.2 & -19.2 & 27.9 & -19.3 & 10.7 & 12.5 & 25.5 & -13.6 & 4.2 & -1.3 & 14.3 \\
\hline & 3. Ölçüm & -20.2 & -2.2 & -19.5 & 28.2 & -21.3 & 11.5 & 12.6 & 27.4 & -12.3 & 6.3 & -9.8 & 18.2 \\
\hline \multirow{3}{*}{ Sürmene } & 1.Ölçüm & -13.6 & -1.6 & -14.2 & 19.7 & -12.9 & 2.9 & 2.2 & 13.5 & -9.9 & 1.8 & -0.4 & 10.2 \\
\hline & 2. Ölçüm & -18.3 & -2.0 & -15.5 & 24.1 & -15.3 & 8.9 & 12.8 & 21.9 & -11.6 & 1.3 & -3.9 & 12.4 \\
\hline & 3. Ölçüm & -20.9 & -2.5 & -18.3 & 27.9 & -16.9 & 10.1 & 13.3 & 23.7 & -13.9 & 3.7 & -2.3 & 14.6 \\
\hline \multirow{3}{*}{ Hıdırnebi } & 1.Ölçüm & -12.6 & -0.5 & -11.6 & 17.2 & -9.4 & 2.2 & 3.9 & 10.1 & -4.2 & 2.6 & -0.6 & 5.1 \\
\hline & 2. Ölçüm & -10.1 & -1.3 & -16.3 & 19.3 & -17.2 & 8.9 & 11.9 & 22.8 & -6.3 & 1.3 & -4.0 & 7.6 \\
\hline & 3. Ölçüm & -17.9 & -3.0 & -18.8 & 26.1 & -16.2 & 9.0 & 13.5 & 23.0 & -10.3 & 4.7 & -4.8 & 12.3 \\
\hline
\end{tabular}

*Standart sapma değerleri parantez içerisinde verilmiştir.

Çizelge 3. Dış ortam testi öncesi ve sonrası için odun örneklerinin LPB direnci verileri.

\begin{tabular}{lllllll}
\hline & \multicolumn{2}{l}{ Kontrol } & X Maddesi & & \multicolumn{2}{c}{ Y Maddesi } \\
\cline { 2 - 7 } Dış Ortam Test Bölgeleri & Basınç Direnci & St sp & Basınç Direnci & St sp & Basınç Direnci & St sp \\
\hline Dış Ortam Testi öncesi & 549.2 & 58.1 & 558.0 & 39.4 & 560.0 & 97.7 \\
\hline Uzungöl & 319 & 94.3 & 467.4 & 92.4 & 459.0 & 84.4 \\
\hline Sürmene & 302 & 96.4 & 450.4 & 81.4 & 415.4 & 87.4 \\
\hline Hıdırnebi & 335 & 90.4 & 510.4 & 95.4 & 475.5 & 94.1 \\
\hline
\end{tabular}




\section{SONUÇLAR VE ÖNERILER}

Doğal dış ortam testine maruz kalan odun yüzeylerinin bozunmasında, birincil (ışık, sıcaklık ve nem) ve ikincil (atmosferik kirlilik, fiziksel stres-yorgunluk, biyolojik saldırı, erozyon ve bileşen uyumsuzluğu) olmak üzere çeşitli faktörlerin etkisi olmaktadır (Özgenç 2014). Bu nedenle, renk değişimi ve LPB direncindeki değişim Sürmene sahilinde, Hıdırnebi ve Uzungöl yaylalarında birbirinden farklı bulunmuştur. En yüksek yüzey deformasyonu ve renk değişimi, Uzungöl yaylasında uygulanan dış ortam testi sonrasında bulunmuştur. Uzungöl yaylasındaki örnek yüzeylerinde kirlilik düzeyinin oldukça yüksek olmasının nedeni hava kirliliği olarak belirlenmiştir. Dış ortam test düzenekleri turizm tesislerine yakın alanda oluşturulduğu için; soba, kalorifer, fırın, araba egzozu vs. kaynaklı hava kirliliği oldukça yüksektir. Ayrıca Hıdırnebi yaylasına kıyasla, Sürmene sahilinde ve Uzungöl yaylasında havadaki nem oranının yüksek olması örnek yüzeylerindeki deformasyonu arttırmıştır. Üç faklı ortamda uygulanan test koşullarında renk değişimine karşı en yüksek korumayı polyester esaslı poliüretan üst yüzey maddesinin ( $Y$ sistemi) sağladığı belirlenmiştir.

Yüzey deformasyonlarını engelleyen poliüretan üst yüzey maddesi uygulanan odun örneklerinde, dış ortam koşullarında liflere paralel basınç direnci değerlerindeki azalma da önemli ölçüde engellemiştir. Ancak, basınç direncindeki azalmaya karşı en yüksek korumayı da polyester esaslı poliüretan ( $Y$ maddesi) üst yüzey maddesi sağlamıştır. N-Methyl-2-pyrolidane (NMP) esaslı ( $X$ maddesi) üst yüzey maddesinin, doğu ladini örneklerinin köşelerinden koparak ayrıldığı için yüksek koruma sağlayamadığı düşünülmüştür.

Bu çalışmanın devamında, poliüretan esaslı bu vernik tiplerine UV absorbe edici pigmentler karıştırılması önerilmektedir. Böylece, dış ortam koşullarında UV absorbe edicinin etkisiyle poliüretan üst yüzey maddesinin sararmasının engellenebileceği tahmin edilmektedir.

\section{TEŞEKKÜR}

Yazar, Karadeniz Teknik Üniversitesi Bilimsel Araştırma Koordinasyon birimine sağladığı araştırma fonu desteği (Proje no: 2009.113.002.1) için teşekkür etmektedir.

\section{KAYNAKÇA}

Ayadi N, Lejeune F, Charrier F, Charrier B ve Merlin A (2003) Color Stability of Heat-Treated Wood During Artificial Weathering, Holz als Roh- und Werkstoff, 61, 221-226.

Burdurlu E ve Özgenç Ö (2009) Effect of Different Layer Structures on Some Resistance Characteristics of High-Pressure Laminates, Forest Products Journal, 59, 4, 69-75.

Chou PL, Chang HT, Yeh TF ve Chang ST (2008) Characterization the Conservation Effect of Clear Coatings on Photodegradation of Wood, Bioresources Technology, 99, 1073-1079.

Croll SG ve Skaja AD (2002) Spestroskopic Adsorption and Effective Dosage in Accelerated Weathering of a Polyester-Urethane Coating, Journal of Materials Science, 37, 4889-4900.

Decker C, Masson F ve Schwalm R (2004) Weathering Resistance of Water-Based UV-Cured Polyurethane-Acrylate Coatings, Polymer Degradation and Stability, 83, 309-320.

Evans DP ve Chowdhury MJA (2010) Photoprotection of Wood Using Polyester-Type UV-Absorbers Derived from the Reaction of 2-hydroxy-4(2,3-epoxypropoxy)-benzophenone with Dicarboxylic Acid Anhydrides, Journal of Wood Chemi. and Techn., 30, 186-204.

ISO 7724(1984) Paints and Varnishes - Colorimetry, International Organization for Standardization.

Nzokou P, Kamdem DP ve Temiz A (2011) Effect of Accelerated Weathering on Discoloration and Roughness of Finished Ash Wood Surfaces in Comporasion with Red Oak and Hard Maple, Progr. in Org. Coatings, 71, 350-354.

Özgenç Ö, Hiziroglu S ve Yıldız UC (2012) Weathering Properties of Wood Species Treated with Different Coating Applications, BioResources, 7, 4, 4875-4888.

Özgenç Ö, Okan OT, Yıldız UC ve Deniz I (2013) Wood Surface Protection against Artificial Weathering with Vegetable Seed Oils, BioResources, 8,4, 6242-6262.

Özgenç Ö, Yıldız ÜC, Yıldız S (2013) Odun Yüzeylerinin Bazı Yeni Nesil Emprenye Maddeleri ve Üst Yüzey İşlemleri ile Dış ortam Etkilerine Karşı Korunması, Artvin Çoruh Üniversitesi, Orman Fakültesi Dergisi, 14, 2, 203-205.

Özgenç Ö, Demirkır C, Yıldız Ü, Çolakoğlu G (2014) The effect of UV irradiation on some technological properties of different polyurethane varnishes coated plywood panels from veneers dried at different temperatures, 45th IRG Annual Meeting, May.

Özgenç, Ö (2014) Doğu Karadeniz Bölgesi Yayla Evlerinde Kullanılan Ahşap Malzemenin dış hava koşullarına karşı dayanımının arttırılması, Doktora Tezi, KTÜ., Fen Bilimleri Enstitüsü, Trabzon. 
Pandey KK (2005) A Note onthe Influence of Extractives on the Photo-Discoloration and Photo-Degradation of Wood, Polym. Degr. and Stabil., 87, 375-379.

Temiz A (2005) Dış Hava Koşullarının Emprenyeli Ağaç Malzemeye Etkileri, Doktora Tezi, KTÜ, Fen Bilimleri Enstitüsü, Trabzon.

TS2595 (1977) Odunun Liflere Paralel Doğrultuda Basınç Dayanımı Tayini, Türk Standartları Enstitüsü, Ankara.

TS EN 927-3(2007) Boyalar ve Vernikler- Dış Mekan Ahşap Malzemeleri için Kaplama Maddeleri ve Kaplama SistemleriBölüm 3: Doğal Hava Şartlarına Maruz Bırakma Deneyi, Türk Standartları Enstitüsü, Ankara.
Williams RS (2005) Handbook of Wood Chemistry and Wood Composites, Chapter 7: Weathering of wood, Forest Products Laboratory, USDA, Forest Service.

Yang XF, Tallman DE, Croll SG, Bierwagen GP (2002) Morphological Changes in Polyurethane Coatings on Exposure to Water, Poly.And Degr. Stabil., 77, 391-396.

Yalınkılıç MK, Imamura Y, Takahashi M, Yalınkılıç AC, Demirci Z (1999) FTIR Studies of the Effects of Outdoor Exposure on Varnish-Coated Wood Pretreated with CCB or Water Repellents, Journal of Coatings Technology, 71, 895, 103-112.

Zhang J, Kamdem DP, Temiz A (2009) Weathering of CopperAmine Treated Wood, Applied Surf. Sci., 256, 842-846. 